\title{
Notas, descrições, sinonímias e revalidação em Hesperandra Arigony, 1977 (Coleoptera, Cerambycidae, Parandrinae)
}

\author{
Antonio Santos-Silva ${ }^{1}$
}

\begin{abstract}
Notes, descriptions, synonymies and reinstatement in Hesperandra Arigony, 1977 (Coleoptera, Cerambycidae, Parandrinae). The genus Hesperandra Arigony, 1977, is divided in three subgenera: Hesperandra s. str., Zikandra subgen. nov. and Tavandra subgen. nov. Keys to the subgenera and species are added. H. glaberrima (Zikán, 1948) is revalidated and redescribed. H. humboldti sp. nov., from Colombia and Ecuador is described. New synonymies established: Hesperandra galapagoensis $($ Van Dyke, 1953) $=$ H. brevicollis (Lameere, 1902); H. scrobriculata (Zikán, 1948) = Acutandra murrayi (Lameere, 1912). The lectotype of Parandra brevicollis Lameere, 1902 is designated.
\end{abstract}

Keywords. Hesperandra; Parandrinae; Tavandra; taxonomy; Zikandra.

\section{INTRODUÇÃO}

O gênero Hesperandra Arigony, 1977, proposto originalmente como subgênero de Parandra Latreille, 1804 é constituído por espécies exclusivamente americanas que podem ser distribuídas em três grupos com base em diferenças da morfologia externa (principalmente da parte ventral da cabeça). Esses grupos são aqui considerados como subgêneros novos.

A alocação de Hesperandra conspicua (Tippmann, 1960) e H. lalannecassouorum Tavakilian, 2000, espécies não examinadas, foi baseada nas descrições originais.

Lameere (1902) dividiu os Parandrini neotropicais com cavidades coxais anteriores fechadas, em dois subgrupos que podiam ser identificados, principalmente, pela ausência ou presença de sulco transversal junto à borda anterior do submento. No primeiro subgrupo, foram incluídas Parandra expectata Lameere, 1902, P. brevicollis Lameere, 1902, P. brachyderes Lameere, 1902, P. villei Lameere, 1885, P. polita Say, 1835, P. colombica White, 1853 e P. longicollis Thomson, 1861 e, no segundo, P. glabra De Geer, 1774 e P. degeeri Thomson, 1867 (na verdade, Hesperandra ubirajarai SantosSilva, 2001). Com exceção de P. expectata, o primeiro subgrupo já constituía claramente um subgênero; porém, o caráter utilizado (ausência de sulco), por si só, não permite sua correta identificação porque existem espécimes do outro subgrupo que não apresentam o sulco que antecede o submento, ou esse é inconspícuo.

LAMEERE (1912) baseando-se principalmente nas cavidades coxais anteriores e nas setas do paroníquio, dividiu o gênero Parandra em quatro subgêneros: Archandra, Neandra,
Parandra s. str. e Stenandra. Archandra correspondia ao grupo com cavidades coxais anteriores fechadas e paroníquio com duas setas e que incluía, além das espécies americanas, Parandra caspia Ménétriès, 1832, da região Paleártica.

Melzer (1919) ao estudar as espécies de Parandrinae ocorrentes no Brasil, agrupou as espécies do subgênero Archandra em duas divisões: "submento sem sulco transversal perto da borda anterior, mas com ponctuação grossa e áspera", que incluía $P$. expectata e $P$. longicollis; "submento com sulco transversal perto da borda anterior e com pontuação mais dispersa, e às vezes nula" que incluía $P$. glabra e $P$. degeeri (na verdade, $H$. ubirajarai).

ZIKÁn (1948) dividiu o subgênero Archandra em duas seções, caracterizadas por apresentarem, ou não, margem anterior do submento elevada. Essas seções foram então divididas em grupos e subgrupos. Esse trabalho não tratou de muitas das espécies ocorrentes nas Américas e P. (Neandra) brunnea (Fabricius, 1798), da Região Neártica, foi considerada como integrante do subgênero Archandra. Apesar disso, a proposta de ZIKÁN (l. c.), de certa forma, já permitia distinguir os três grupos considerados, agora, como subgêneros de Hesperandra.

Arigony (1977) dividiu o subgênero Archandra em dois: Archandra (espécie-tipo, Parandra caspia Ménétriès, 1832) e Hesperandra (espécie-tipo, Parandra expectata Lameere, 1902), baseando-se na forma dos palpos maxilares, do lábio e das mandíbulas. ARIGONY (1978) acrescentou aos caracteres distintivos dos dois subgêneros o número de setas no paroníquio: duas em Archandra e duas ou mais em Hesperandra.

1. Museu de Zoologia, Universidade de São Paulo. Caixa Postal 42594, 04299-970 São Paulo-SP, Brasil. 
ViLLIERS (1980), estudando os Cerambycidae das Antilhas Francesas, elevou Hesperandra a gênero.

Santos-Silva (2002) elevou Neandra e Archandra à categoria de gênero; dividiu Parandra em dois subgêneros $[P$. (Parandra) e $P$. (Birandra)] e propôs um novo gênero, Acutandra.

As siglas mencionadas correspondem às seguintes instituições: FIOC, Fundação Instituto Oswaldo Cruz, Rio de Janeiro; IAHC, Instituto de Investigación de Recursos Biológicos Alexander von Humboldt, Villa de Leyva; MCNZ, Museu de Ciências Naturais, Fundação Zoobotânica do Rio Grande do Sul, Porto Alegre; MNHN, Muséum National d'Histoire Naturelle, Paris; MNRJ, Museu Nacional, Universidade Federal do Rio de Janeiro, Rio de Janeiro; MZSP, Museu de Zoologia, Universidade de São Paulo, São Paulo; UNCB, Museo de Historia Natural, Universidad Nacional de Colombia, Bogotá.

\section{Acutandra murrayi (Lameere, 1912)}

Parandra Murrayi Lameere, 1912: 115.

Parandra (Parandra) Murrayi; Lameere, 1913: 6.

Parandra (Parandra) murrayi; Monné, 1994: 3.

Parandra (Archandra) scrobriculata Zikán, 1948: 28. Syn. nov.

Parandra (Hesperandra) scrobriculata; Arigony, 1978: 150, figs. 2425; Monné, 1994: 9.

Acutandra murrayi; Santos-Silva, 2002: 51.

Hesperandra scrobriculata (Zikán, 1948) deve ser removida do gênero Hesperandra. Examinei o holótipo e uma outra fêmea determinada por Zikán (citada em ARIGONY 1978). Realmente, o holótipo está danificado conforme citou Arigony (l.c.), faltando: cabeça, protórax, propernas, mesoperna direita e tarsômeros III-V da metaperna esquerda. Os dois exemplares pertencem à mesma espécie: Acutandra murrayi (Lameere, 1912). Em $A$. murrayi, a abertura das cavidades coxais anteriores pode ser estreita, como ocorre na fêmea de Hansa Humboldt (atual Corupá), figurada por ArIGONY (op. cit.). Caracteres como pilosidade das mandíbulas, forma do pronoto, pontuação e elevação da margem anterior do submento são variáveis. ZIKÁn (l. c.) alocou P. (Archandra) scrobriculata, no seu subgrupo " $\mathrm{A}$ ": "espécies de corpo deprimido e escultura fina; margem interna das mandíbulas munidas de um dente; bordas laterais do pronoto estreitas, com os cantos anteriores arredondados; paroníquios tarsais com duas cerdas". No entanto, disse, ao referir-se à espécie em questão: "mandíbulas, cabeça, pronoto e élitros com puncturação grosseira e densa", que confere com $A$. murrayi. Pelo exposto, proponho a sinonímia de $H$. scrobriculata $\operatorname{com} A$. murrayi.

Material examinado (Acutandra murrayi). BRASIL. Minas Gerais: Passa Quatro (Fazenda dos Campos), 1.III.1918, Zikán col. Rio de Janeiro: Itatiaia, III.1959, Diringshofen.; II.1966, Diringshofen.; II.1969, Diringshofen. São Paulo: Campos do Jordão, III.1945, Wygodzinsky col.; Paranapiacaba, 22.II.1925, Spitz col.; 12.II.1928, Spitz col.; II.1933, Sptiz col. Santa Catarina: São Bento do Sul (Rio Vermelho), I.1957, Diringshofen. Todos os espécimes são fêmeas da coleção MZSP.
Chave para os subgêneros de Hesperandra

1. Projeção da borda ocular posterior não-saliente (Fig. 4). Submento não-deprimido, glabro ou com pêlos muito curtos e muito esparsos (se houver pêlos longos, esses são sempre raros); pontuação geralmente fina (Fig. 22). Carena ventral das genas inconspícua ou larga e pouco elevada ............. Zikandra subgen. nov.

Projeção da borda ocular posterior saliente ou muito saliente (Figs. 31, 34, 35, 63). Submento deprimido ou não, com pêlos longos e abundantes ou curtos e esparsos; pontuação grossa (Fig. 47). Carena ventral das genas estreita e elevada, ausente ou apenas indicada

2(1). Carena ventral das genas estreita e elevada (Fig. 48) Tavandra subgen. nov.

Carena ventral das genas ausente ou apenas indicada (Fig. 23) HesperandraArigony, 1977

\section{Hesperandra (Zikandra) subgen. nov.}

Espécie-tipo: Attelabus glaber De Geer, 1774.

Etimologia. Homenagem ao entomologista J. F. Zikán, que descreveu muitas espécies do gênero.

Borda ocular posterior (Fig. 4) não-saliente. Submento nãodeprimido, pouco ou não-enegrecido, estreito, glabro ou com raros pêlos muito curtos (alguns espécimes, além dos pêlos muito curtos, apresentam raros pêlos longos); borda anterior elevada, antecedida ou não de sulco; pontuação variável (inconspícua, fina ou moderadamente grossa). Área ventral das genas (Figs. 23, 27) com carena larga ou inconspícua, geralmente mais alta do que o submento e não atinge a área póstero-inferior dos olhos (exemplares com carena relativamente estreita, podem ser reconhecidos pela forma e pilosidade do submento). Mandíbulas grandes e falciformes nos machos major, menores e menos arqueadas nos machos minor; fêmeas com mandíbulas não falciformes. Antenas (Figs. $5,6,10)$ : carenas das fossetas sensoriais dos antenômeros IIIXI variáveis, desde evidentes até ausentes (algumas espécies apresentam mais de uma forma de carena ao longo dos antenômeros). Protórax com marginação lateral completa ou incompleta nos machos e completa nas fêmeas. Tarsômero II (Figs. 2, 3), nas três pernas, com aproximadamente metade do comprimento do tarsômero I.

Comentários. H. (Zikandra) difere de $H$. (Tavandra) e $H$. (Hesperandra), por apresentar projeção da borda ocular posterior não-saliente; submento não-deprimido, glabro ou com pêlos muito curtos e esparsos (raramente há alguns pêlos longos), escultura formada por pontos finos concentrados ou não e margem anterior elevada nos dois sexos; carena ventral das genas inconspícua ou larga e pouco elevada (raramente nitidamente elevada). $H$. (Tavandra) apresenta: projeção da 

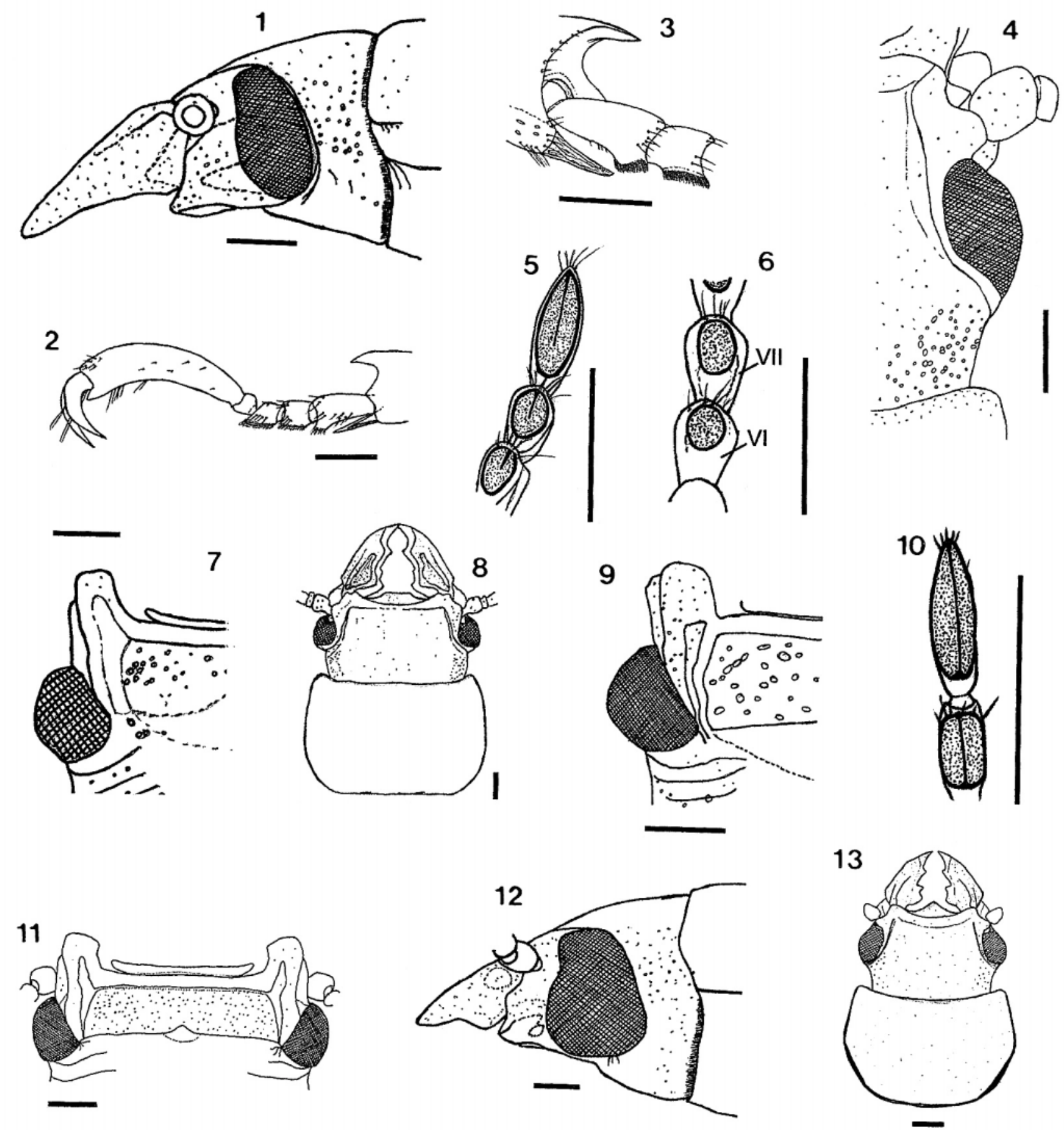

Figs. 1-13. 1, $H$. (Zikandra) brasilica, macho, cabeça (lateral); 2 - 4, H. (Z.) glabra, macho: 2 e 3, tarsômeros; 4, projeção da borda ocular posterior; 5 - 6, H. (Z.) minuscula, macho: 5, últimos antenômeros; 6, antenômeros VI - VII; 7, H. (Zikandra) separanda, macho, gena e submento; 8, $H$. (Z.) ubirajarai, fêmea, cabeça e pronoto (dorsal); 9, H. (Z.) brasilica, macho major, gena e submento; 10, H. (Z.) separanda, macho, últimos antenômeros; 11, H. (Z.) monnei, macho, genas e submento; 12, H. (Z.) glabra, fêmea, cabeça (lateral); 13, H. (Z.) minuscula, fêma, cabeça e pronoto (dorsal). Barra $=1 \mathrm{~mm}$. 

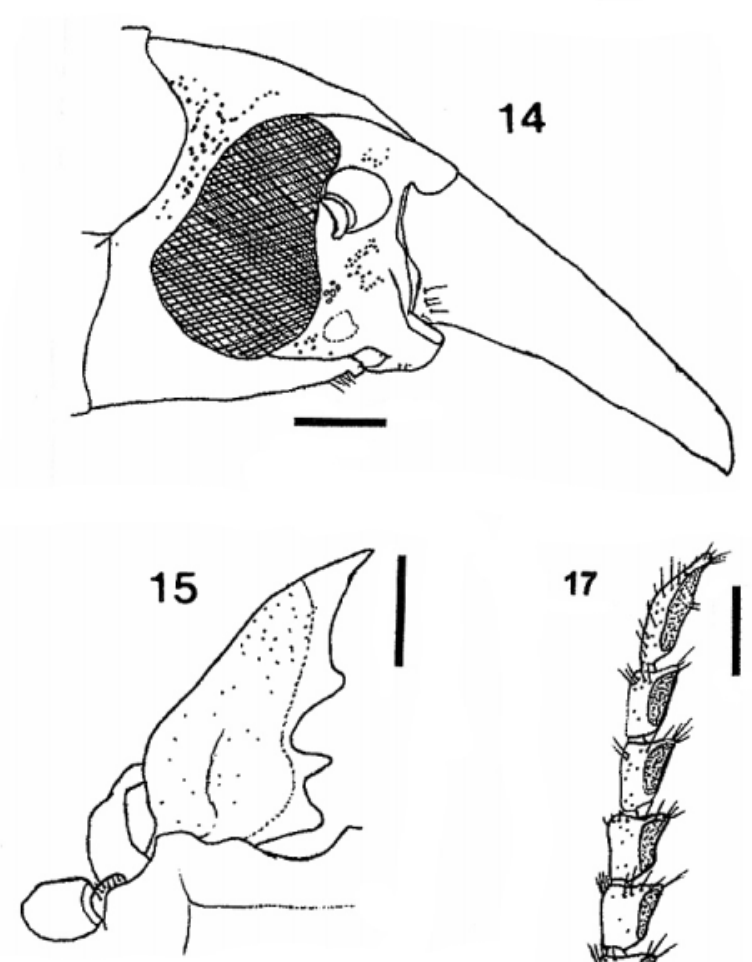

16

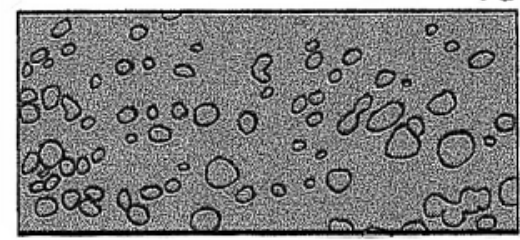

LATERAL $\longrightarrow$ VERTICE
Metepisternos glabros ou com pilosidade restrita ao terço basal ..... 2

2(1). Antenômeros IV-VI (Fig. 19) mais largos do que longos (excluíndo a área sensorial); antenômero X cerca de um quarto mais curto que o XI. BRASIL (Bahia, Goiás) H. (Zikandra) glaberrima (Zikán, 1948)

Antenômeros IV-VI (Fig. 17) mais longos do que largos (excluíndo a área sensorial); antenômero $\mathrm{X}$, no mínimo, um terço mais curto que o XI (freqüentemente mais curto)

3(2). Protórax dos machos com marginação lateral completa; fêmeas com olhos largos (Fig. 12). MÉXICO, AMÉRICA CENTRAL (inclusive parte das Antilhas) e AMÉRICA DO SUL

H. (Zikandra) glabra (De Geer, 1774)

Protórax dos machos com marginação lateral incompleta; machos (Fig. 1) e fêmeas com olhos estreitos .......... 4

4(3). Área sensorial dos antenômeros III-X (Figs. 5, 6) não carenada ou com carena incompleta (quando presente, a carena é sempre pouco saliente). BRASIL (Minas Gerais, Rio de Janeiro e São Paulo)

H. (Zikandra) minuscula (Zikán, 1948)

Área sensorial dos antenômeros III-X dividida por carena evidente em toda a extensão (Fig. 10) 5

5(4). Margem anterior do submento precedida por sulco profundo e bem delimitado; élitros com pontos microscópicos; ápice do labro das fêmeas reto e largo (Fig. 8). BRASIL (Minas Gerais, Rio de Janeiro, São Paulo e Santa Catarina)

H. (Zikandra) ubirajarai Santos-Silva, 2001

Figs. 14-17. H. (Zikandra) humboldti sp. nov.: 14, holótipo macho, cabeça (lateral); 15, parátipo fêmea, mandíbula esquerda (dorsal); 16, holótipo macho, pontuação da região posterior dos olhos (aumento de 50x); 17, holótipo macho, antena. Barra $=1 \mathrm{~mm}$.

borda ocular posterior nitidamente saliente; submento deprimido, com pêlos longos e abundantes, pontuação grossa e margem anterior do submento não-elevada nos machos; carena ventral das genas estreita e elevada. Em $H$. (Hesperandra): projeção da borda ocular posterior pouco saliente; submento, em geral, plano ou fracamente intumescido, com pêlos curtos e esparsos, pontuação muito grossa e anastomosada e margem anterior inteiramente elevada nos dois sexos ou, nos machos, elevada apenas nas laterais; carena ventral das genas ausente ou apenas indicada.

\section{Chave para as espécies de Hesperandra (Zikandra)}

1. Metepisternos (Fig. 26) com pilosidade conspícua em toda a extensão. (Figs. 24, 25). COLÔMBIA
6(5). Cantos anteriores do pronoto dos machos angulosos; área lateral das genas com pontos muito escassos e pequenos em direção ao ápice nos dois sexos (Fig. 7). BRASIL (Minas Gerais, São Paulo, Paraná, Santa Catarina e Rio Grande do Sul)

H. (Zikandra) separanda (Zikán, 1948)

Cantos anteriores do pronoto dos machos arredondados; área lateral das genas com pontos maiores e mais cerrados nos dois sexos (Fig. 9) 7

7(6). Submento com pontos pequenos, abundantes (Fig. 11); borda anterior do pronoto fortemente côncava. BRASIL (Rio de Janeiro, São Paulo e Santa Catarina) H. (Zikandra) monnei Santos-Silva, 2001 Submento com pontos maiores, abundantes ou não (Fig. 9). BRASIL (Minas Gerais, Rio de Janeiro, São Paulo e Santa Catarina)

H. (Zikandra) brasilica (Zikán, 1948) 

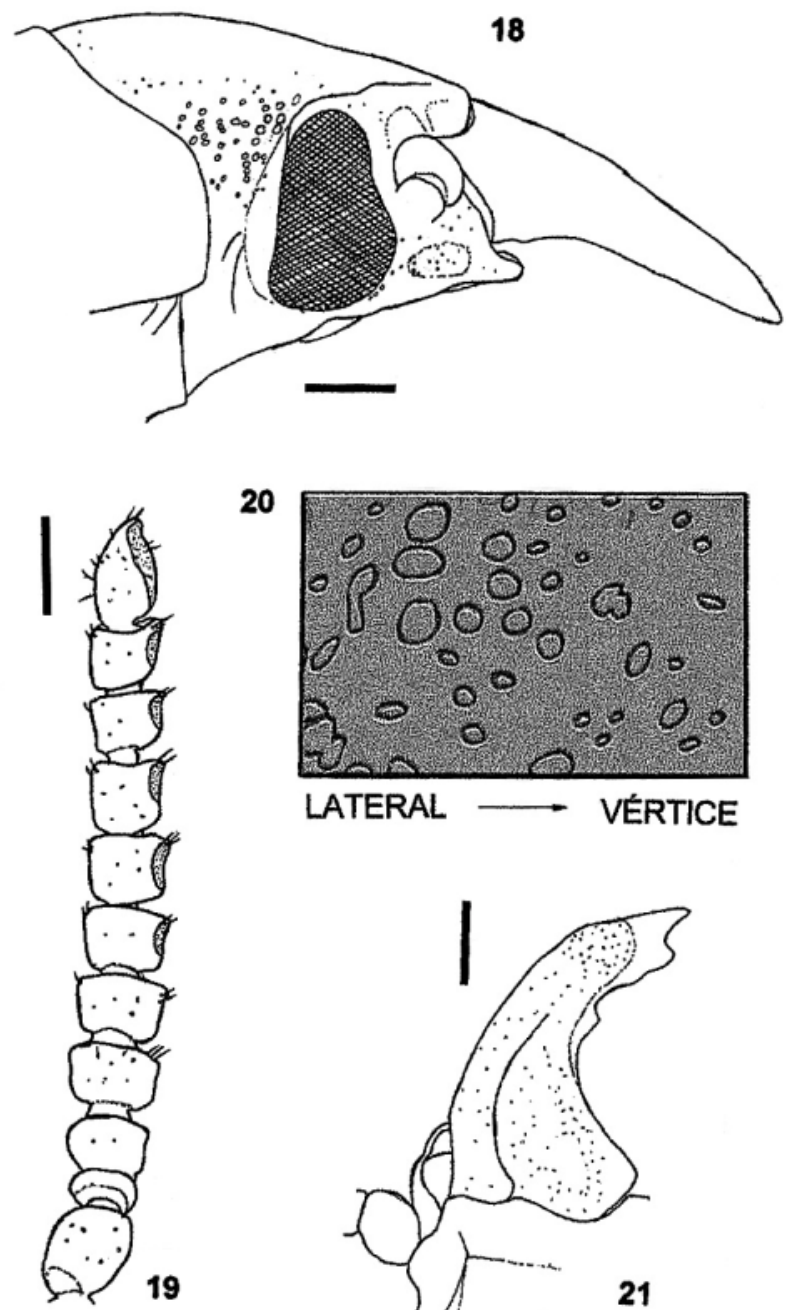

20
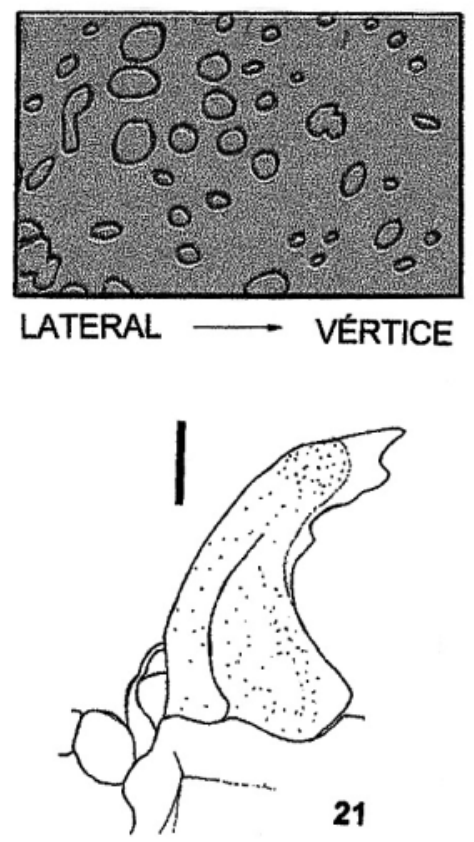

Figs. 18-21. H. (Zikandra) glaberrima, macho: 18, cabeça (lateral); 19, antena; 20, pontuação da região posterior dos olhos (aumento de $50 \mathrm{X}$ ); 21, mandíbula esquerda (dorsal). Barra $=1 \mathrm{~mm}$.

\section{Hesperandra (Zikandra) humboldti sp. nov.}

(Figs. 14 -17, 23 - 26)

Etimologia. A espécie é dedicada ao naturalista Alexander von Humboldt.

Macho (Fig. 24). Tegumento castanho, cabeça e mandíbulas castanho-escuras. Vértice e fronte com pontos microscópicos esparsos. Região posterior dos olhos com pontuação forte (Fig. 16). Carena ocular baixa, delimitada por sulco raso que se inicia junto à sutura epistomal e termina próximo à metade da borda ocular posterior; pontuação microscópica. Suturas epistomal e clípeo-labral indicadas. Ápice do labro truncado e pouco projetado, com diminutos pêlos esparsos. Borda ocular (Fig. 14) não-projetada. Genas (Fig. 14) com pontos pequenos e esparsos, mais visíveis junto à fóvea antenal; ápice projetado e arredondado; área lateral com depressão próxima aos olhos; área ventral não-carenada, muito curta e com sulco profundo.
Submento (Fig. 23) com borda anterior estreita e elevada, antecedida por sulco raso; pontuação muito esparsa (os pontos variáveis: microscópicos ou pequenos); pêlos das regiões laterais microscópicos e pêlos da área central (Fig. 14), junto à borda anterior, longos e raros. Mandíbulas (Fig. 24) com pontuação microscópica e esparsa, mais cerrada no terço apical; dente apical externo aguçado e dente apical interno menor e mais largo; ápice liso e ligeiramente alargado; dente da borda interna pequeno, aguçado e localizado aproximadamente no meio; borda interna microrrugosa e glabra; carena dorsal baixa, larga na base e estreita em direção ao terço apical, onde termina; depressão triangular dorsal rasa; depressão ventral pequena e rasa; base lateral com alguns pêlos curtos.

Antenas (Figs. 17, 24) atingem a borda posterior do protórax. Antenômeros III-XI com a área sensorial dividida por carena completa e muito alta e com pêlos curtos nos ápices dorsais e ventrais (a concentração e comprimento desses pêlos, aumenta em direção ao antenômero XI). Antenômero XI com pêlos em toda a região dorsal e alguns na área sensorial.

Protórax (Fig. 24) transverso, com marginação lateral completa; ângulos anteriores e posteriores arredondados (estes últimos fortemente). Pronoto liso. Prosterno liso e glabro no disco; laterais com raros pêlos próximos às procoxas. Ápice do processo prosternal projetado. Mesosterno liso e glabro no disco, piloso nas laterais. Mesepisternos e mesepimeros pilosos. Metasterno liso, glabro e muito brilhante no disco; bordas laterais e área junto às mesocoxas com pontos diminutos e pilosidade bem visível. Metepisternos (Fig. 26) com pontos pequenos e pilosidade conspícua em toda a extensão. Élitros (Fig. 24) lisos.

Quatro primeiros urosternitos com pontos rasos e esparsos e pêlos dispersos. Último urosternito com asperezas dispersas e pêlos longos na área centro-apical; borda enegrecida e com franja de pêlos; ápice com depressão central.

Coxas pilosas, mais evidentemente as metacoxas. Fêmures e trocanteres com pêlos mais evidentes no terço apical-ventral. Paroníquios com três setas.

Fêmea (Fig. 25). Aspecto geral muito semelhante ao do macho. Mandíbulas (Fig. 15) com ápice largo (distância entre as pontas dos dentes apicais) e dente apical interno pequeno; borda interna com reentrância central, seguida de um dente aguçado; carena e depressão dorsais inconspícuas. Pontuação dos metepisternos e das áreas laterais do metasterno, mais forte que no macho.

Dimensões, em mm (macho/fêmea). Comprimento total (exclusive mandíbulas), 26,0/27,5; comprimento do protórax no centro, 4,9/5,1; maior largura do protórax, 7,6/7,7; comprimento dos élitros, 17,5/18,6; largura umeral, 7,7/8,5.

Comentários. A nova espécie é muito semelhante, no aspecto geral, a alguns exemplares de H. glabra (De Geer, 1774). Difere pela pilosidade conspícua dos metepisternos e partes laterais do metasterno. É provável que esta seja a espécie que ARIGONy (1978) confundiu com $H$. brevicollis, embora a descrição e as figuras não permitam uma conclusão definitiva. As figuras apresentadas por ARIGONY (l. c.), que correspondem 

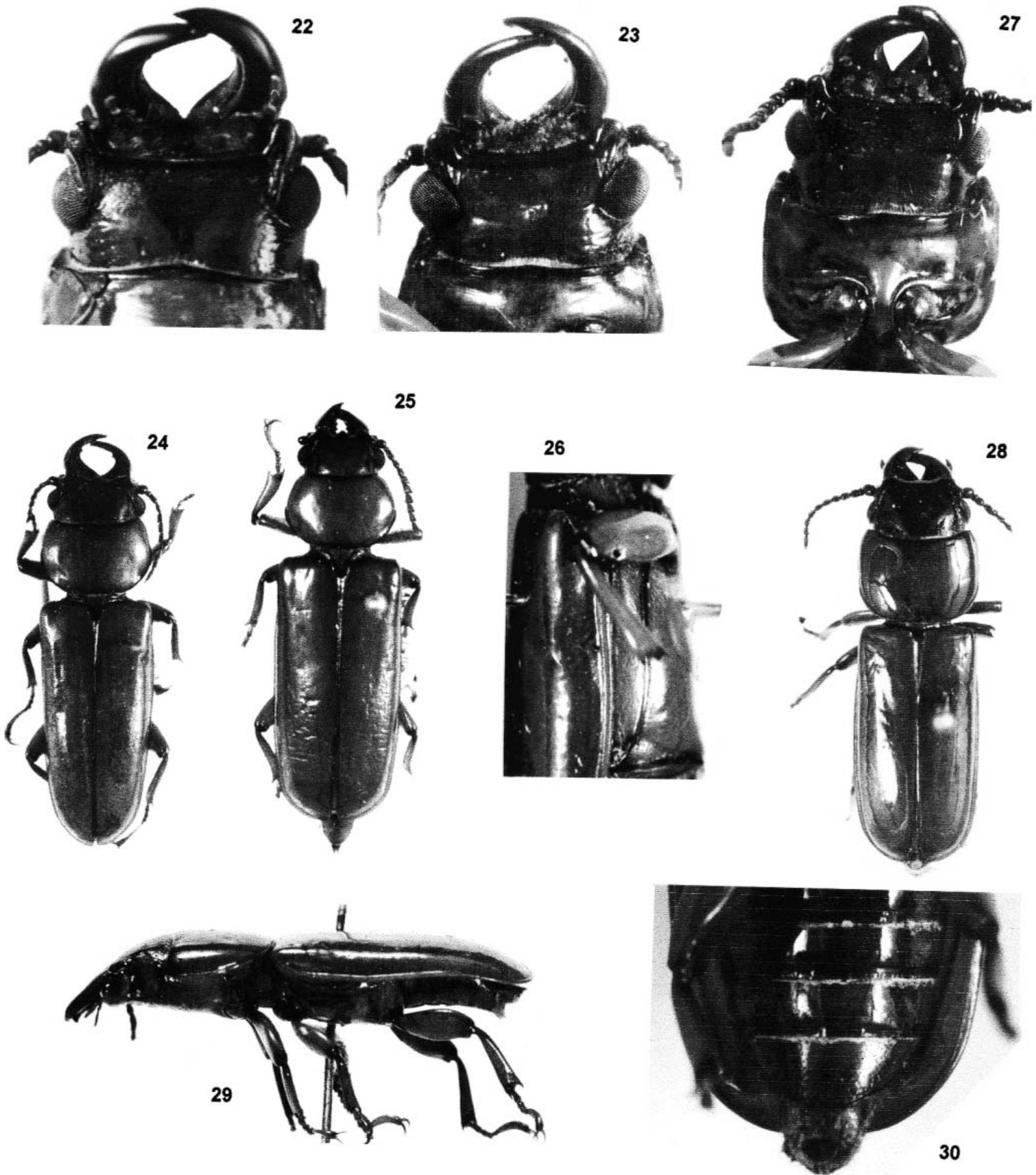

Figs. 22-30. 22, $H$. (Zikandra) glabra, macho, cabeça (ventral); 23 - 26, H. (Z.) humboldti sp. nov. (holótipo macho e parátipo fêmea): 23, macho, cabeça (ventral); 24, macho, vista dorsal; 25, fêmea, vista dorsal; 26, fêmea, metepisterno e metasterno (lateral); 27 - 30, H. (Zikandra) glaberrima, macho: 27, cabeça e protórax (ventral); 28, vista dorsal; 29, vista lateral; 30, urosternitos. 
às vistas dorsal e ventral de um mesmo macho e não macho $\mathrm{e}$ fêmea, deixam claro que se trata de uma espécie com os caracteres do subgênero $H$. (Zikandra): forma da borda posterior dos olhos, submento e carena genal. H. brevicollis foi alocada, neste trabalho, em $H$. (Tavandra).

Material-tipo. Holótipo macho, procedente da COLÔMBIA, Risaralda: Santuario Campamento (2200 m), 1.III.1990, (n ${ }^{\circ}$ 01282), F. Fernández col. (IAHC). Parátipos: COLÔMBIA, Valle del Cauca: cercanias de Cali (1150m), fêmea, 1995, C. Medina col. (MZSP); Cali (km 18, Rodovia para Buenaventura), fêmea, 25-30.IX.1978, Mac. A. Tidwell col. (FSCA); fêmea, 29.I-04.II.1979, Mac. A. Tidwell col. (FSCA); Meta: Humadea, macho, 6.IX.1999, O. Higuera \& R. Quevedo col. (UNCB); EQUADOR, Napo: vizinhança de Cosanga $(2050 \mathrm{~m})$, fêmea, 1730.IX.1996, E. Giesbert col. (MZSP).

\section{Hesperandra (Zikandra) glaberrima (Zikán, 1948), revalidada, comb. nov.}

(Figs. 18-21, 27-30)

Parandra (Archandra) glaberrima Zikán, 1948: 35; Arigony, 1978: 143 ( syn.); Monné, 1994: 7 (cat., in syn.); Tavakilian, 2000: 160 (in syn.).

Parandra glaberrima; Monné \& Giesbert, 1994: 1 (cat., in syn.); Maes et al., 1994: 2 (cat., in. syn.).

Redescrição. Macho (Fig. 28). Tegumento castanho muito brilhante. Cabeça, mandíbulas, antenas e ápices dos fêmures castanho-escuros. Fronte com pontos pequenos, esparsos. Vértice com pontuação microscópica. Clípeo com pontos pequenos mais concentrados nas laterais. Labro com pontos pequenos; ápice com truncatura estreita, projetado (não ultrapassa os cantos anteriores da cabeça) e com pêlos curtos na borda anterior. Sutura epistomal indicada nas laterais. Sutura clípeo-labral indicada. Carena ocular baixa e bem delimitada por sulco profundo. Região posterior dos olhos (Fig. 20) com pontos fortes (às vezes anastomosados). Olhos (Fig. 18) largos. Genas com pontuação esparsa (pontos pequenos), mais concentrada junto aos olhos; ápice projetado, achatado e semiarredondado; carena genal (Fig. 27) inconspícua; área ventral com depressão circular próxima ao ápice. Submento (Fig. 27) com borda anterior pouco elevada (a elevação larga, mate, de superfície sinuosa, ligeiramente mais saliente no centro); escultura formada por pontos pequenos esparsos, concentrados na região central junto à gula, e diminutos e raros pêlos nas laterais. Mandíbulas (Fig. 21) alargadas na base, com esparsos pontos pequenos no dorso e laterais, cerrados em direção ao ápice e borda interna; ápice mate, com dente apical externo aguçado e dente apical interno rombo; dente da borda interna pequeno, obtuso, localizado no terço apical; carena dorsal baixa e depressão dorsal rasa.

Antenas (Fig. 19) curtas. Antenômeros IV-VI mais largos do que longos. Antenômeros III-XI com área sensorial dividida por carena baixa. Antenômero XI pouco mais longo que o X, com pêlos curtos no dorso e junto ao ápice da carena da área sensorial.

Protórax transversal, com marginação lateral completa (Fig. 28); ângulos anteriores obtusos e os posteriores arredondados; borda anterior côncava. Pronoto com pontos microscópicos e esparsos. Prosterno liso e glabro. Processo prosternal de ápice largo, não-projetado. Mesosterno liso e glabro no disco, com pontos e pêlos esparsos nas laterais. Mesepisternos e mesepimeros glabros, com raros pontos. Metasterno liso e glabro em quase toda extensão (raros pêlos e pontos junto às metacoxas). Metepisternos glabros com pontos pequenos na área junto aos mesepimeros. Élitros (Figs. 28, 29) completamente lisos.

Quatro primeiros urosternitos (Fig. 30) com pontuação mais concentrada nas laterais e pêlos dispostos na borda posterior. Último urosternito com pontuação e pilosidade abundante na área centro-posterior; borda com franja de pêlos e ápice truncado.

Procoxas com pêlos esparsos evidentes; mesocoxas glabras; metacoxas com pêlos curtos e esparsos. Trocanteres e fêmures glabros. Tíbias com pêlos curtos no terço apical. Paroníquios com dois pares de setas.

Fêmea desconhecida.

Dimensões, em mm (macho). Comprimento total (exclusive mandíbulas), 20,8-21,2; comprimento do protórax no centro, 4,5-4,8; maior largura do protórax, 6,4-6,6; comprimento dos élitros, 13,0-13,1; largura umeral, 6,2-6,3.

Comentários. Arigony (1978), ao sinonimizar Parandra glaberrima com Hesperandra glabra, afirmou: “... porém, ao descrever as "antenas mais curtas", não cita dimensões nem relaciona com qualquer outra parte do corpo do inseto". No entanto, ZIKÁN (1948), na chave apresentada no mesmo trabalho em que descreveu a espécie, declarou: "Antenas curtas, de comprimento igual ao do pronoto". ARIGONY (l. c.), também não disse se viu ou não o holótipo.

$H$. glaberrima diferencia-se de $H$. glabra por: pronoto dos machos não notavelmente abaulado nos dois terços láteroanteriores; antenas mais curtas que a largura do pronoto; antenômeros IV-VI mais largos do que longos; antenômero XI pouco mais longo do que o X; borda anterior do submento mais larga; mesepimeros e mesepisternos praticamente lisos.

Material examinado. BRASIL. Bahia: Rio Mucuri, holótipo macho, sem data, no 11.706, Bruno Pohl col. (FIOC). Goiás: Vianápolis, 2 machos, III.1930, R. Spitz col. (MZSP)

\section{Hesperandra (Tavandra) subgen. nov.}

Espécie-tipo: Parandra longicollis Thomson, 1861.

Etimologia. Homenagem a Gérard L. Tavakilian, entomologista do MNHN, pelas inúmeras gentilezas.

Projeção da borda ocular posterior (Figs. 31, 34, 35) saliente ou muito saliente (em geral menos projetada nas fêmeas). Submento (Figs. 47, 48, 49) largo, geralmente enegrecido, deprimido (mais fortemente nos machos), com pêlos esparsos (às vezes, relativamente abundantes) e evidentes; borda anterior não-elevada ou inconspícua nos machos (raramente com elevação nítida), estreita e elevada nas fêmeas. Área ventral das genas (Fig.48) com carena estreita, mais alta que o 

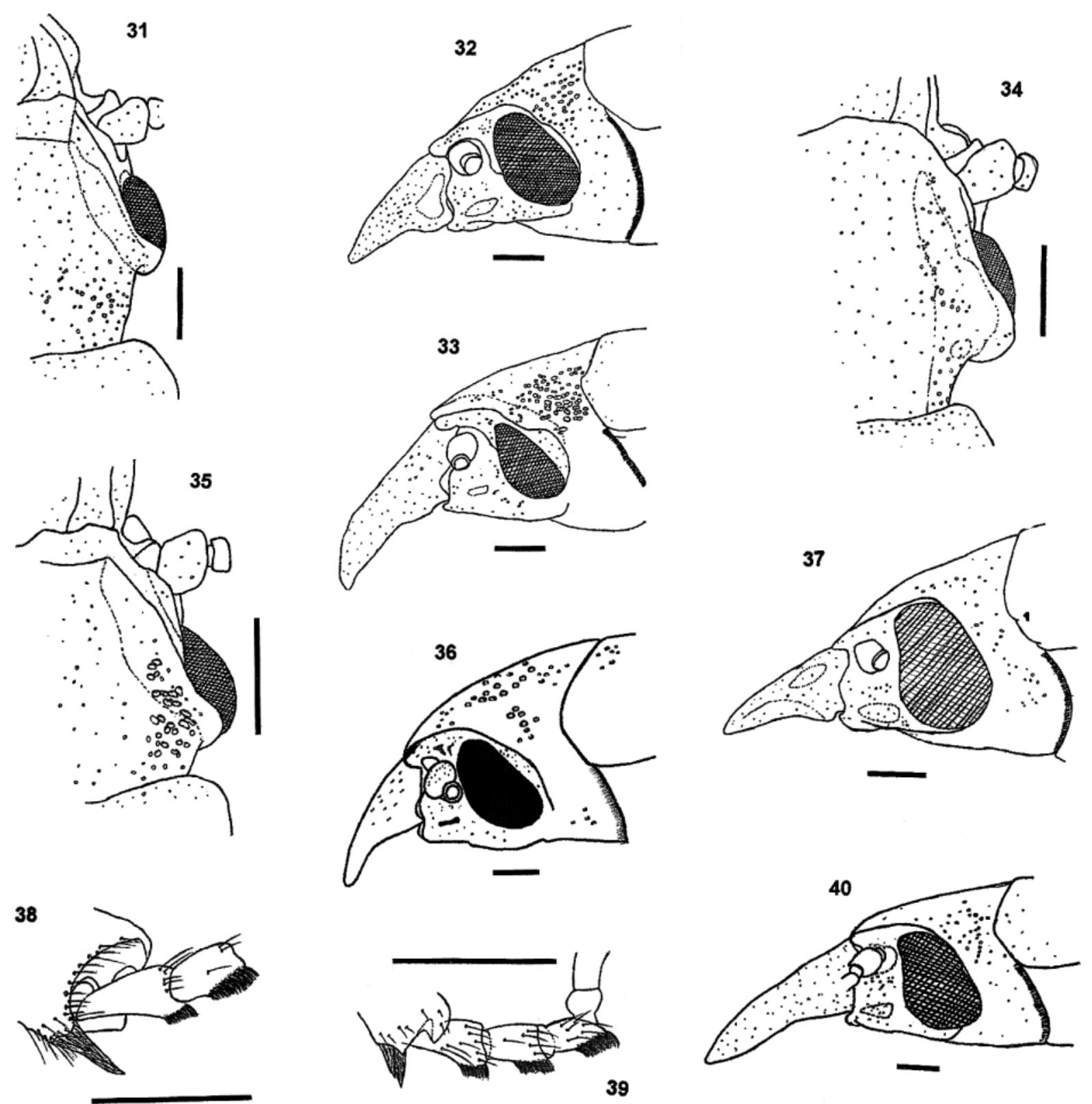

Figs. 31-40. 31 - 34, H. (Tavandra) longicollis: 31, fêmea, projeção da borda ocular posterior; 32, fêmea, cabeça (lateral); 33, macho, cabeça (lateral); 34, macho, projeção da borda ocular posterior; 35, H. (Tavandra) brevicollis, macho, projeção da borda ocular posterior; 36, $H$. (T.) lalannecassouorum, macho, cabeça (lateral, desenho de G. Tavakilian); 37 e 40, H. (T.) guianensis, parátipos, cabeça (lateral): 37, fêmea; 40, macho; 38 - 39, H. (T.) villei, macho, tarsômeros. Barra $=1 \mathrm{~mm}$.

submento. Mandíbulas grandes e falciformes nos machos (Figs. 41, 43, 45); menores nas fêmeas (Figs. 42, 44, 46, 50), pouco arqueadas ou retilíneas na face externa. Antenas com fossetas sensoriais divididas por carena nos antenômeros III-XI. Protórax com ângulos posteriores arredondados ou obtusos; marginação lateral completa. Tarsômeros II (Figs. 38, 39) com aproximadamente três quartos do comprimento do primeiro.

Chave para as espécies de Hesperandra (Tavandra)

1. Metepisternos com pêlos evidentes (Fig. 51)
Metepisternos glabros ou com pilosidade esparsa, geralmente mais visível só na área anterior 5

2(1). Metasterno (Fig. 51) com pilosidade igual à dos metepisternos, exceto uma faixa central do disco (Figs. 50, 52, 53). NICARÁGUA (?), VENEZUELA, COLÔMBIA, EQUADOR

H. (Tavandra) colombica (White,1853)

Metasterno com pilosidade mais esparsa que a dos metepisternos, mais concentrada próximo às mesocoxas e junto aos metepisternos 
3(2). Dente da margem interna das mandíbulas dos machos, grande e localizado no centro (Fig. 43); nas fêmeas, margem interna das mandíbulas fortemente côncava (Fig. 44). MÉXICO (Michoacán, Colima, Morelos, Jalisco) ... H. (Tavandra) brachyderes (Lameere, 1902)

Dentes da margem interna das mandíbulas dos machos, menores e localizados entre o meio e o ápice; margem interna das mandíbulas das fêmeas com reentrância central

4(3). Corpo robusto (Fig. 56); pontuação elitral microscópica; ápice do labro truncado. EQUADOR

H. (Tavandra) brevicollis (Lameere, 1902)

Corpo esguio (Fig. 55); pontuação elitral muito fina, porém distinta; ápice do labro aguçado. VENEZUELA, COLÔMBIA, EQUADOR, PERU

H. (Tavandra) villei (Lameere, 1885)

5(1). Dente da margem interna das mandíbulas dos machos localizado no meio ou pouco atrás (Figs. 41, 54); margem interna das mandíbulas das fêmeas côncava (Fig. 42). ESTADOS UNIDOS, MÉXICO, AMÉRICA CENTRAL, GUIANA, COLÔMBIA, EQUADOR, PERU, BOLÍVIA, INGLATERRA (introduzida) ........ H. (Tavandra) polita (Say, 1835)

Dente da margem interna das mandíbulas dos machos localizado no terço apical (Fig. 45); margem interna das mandíbulas das fêmeas com reentrância central (Fig. 46) ... 6

6(5). Olhos largos (Figs. 37, 40); borda ocular posterior pouco projetada em vista lateral. GUIANA FRANCESA ........ H. (Tavandra) guianensis Tavakilian, 2000 Olhos mais estreitos (Fig. 33); borda ocular posterior projetada em vista lateral (Fig. 31) .

7(6). Borda posterior dos olhos abruptamente elevada a partir do meio (Figs. 32, 33). EUA até ARGENTINA ......... H. (Tavandra) longicollis (Thomson, 1861) Borda posterior dos olhos não abruptamente elevada (Fig. 36). GUIANA FRANCESA . ..H. (Tavandra) lalannecassouorum Tavakilian, 2000

Hesperandra (Tavandra) brevicollis (Lameere, 1902)

(Figs. 56 - 58)

Parandra brevicollis Lameere, 1902: 70.

Parandra (Archandra) brevicollis; Lameere, 1913: 4 (cat.); 1919: 15; Blackwelder, 1946: 551 (cat.).

Parandra (Hesperandra) brevicollis; Arigony, 1978: 137; Monné \& Giesbert, 1994: 1; Monné, 1994: 5.

Parandra galapagoensis Van Dyke, 1953: 127; Linsley \& Chemsak, 1966: 203; Linsley \& Usinger, 1966: 152; Linsley, 1977: 23 (distr.); Gara \& Onore, 1989: 234. Syn. nov.

Parandra (Archandra) galapagoensis; Arigony, 1971: 17.

Parandra (Hesperandra) galapagoensis; Arigony, 1978: 155; Monné \& Giesbert, 1994: 1; Monné, 1994: 6.
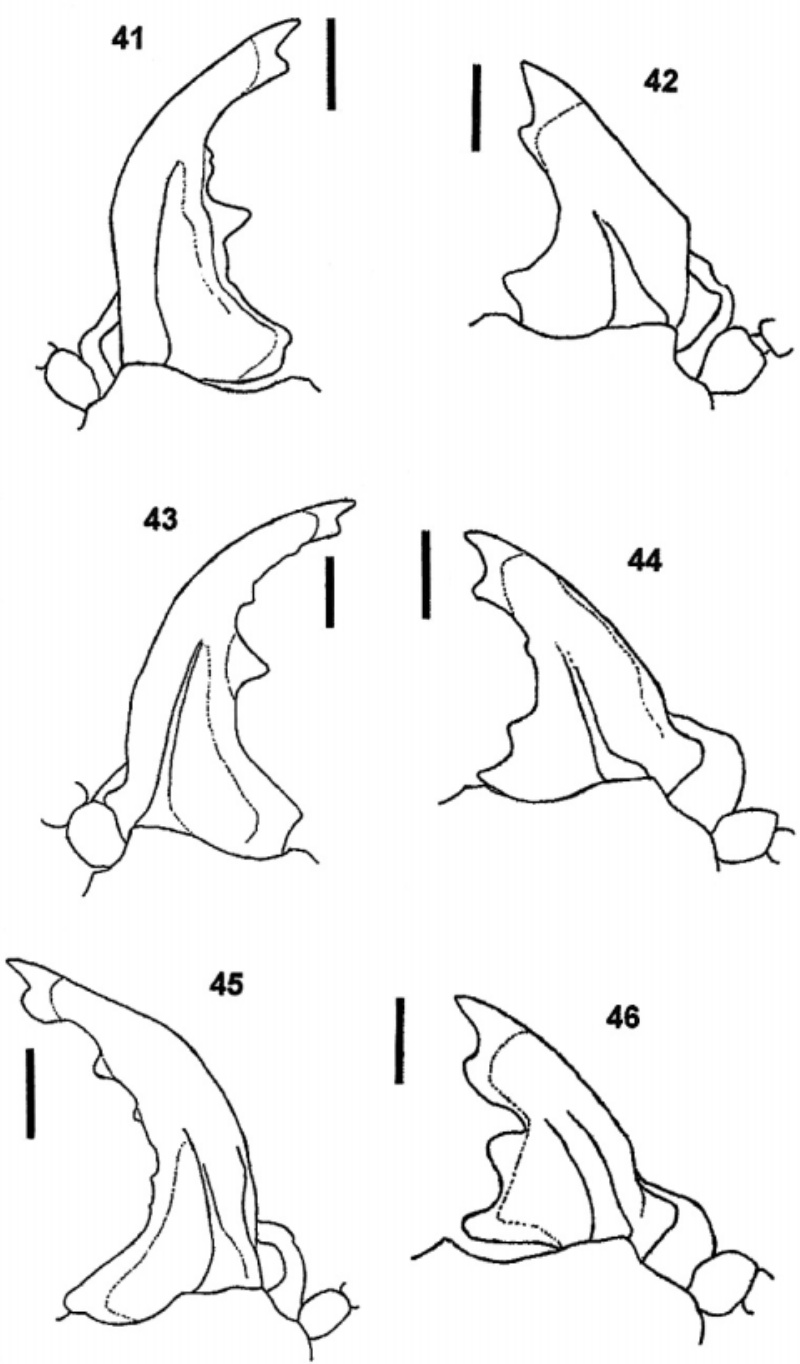

Figs. 41-46. Mandíbulas. 41 - 42, $H$. (Tavandra) polita: 41, macho; 42 , fêmea; 43 - 44, $H$. (T.) brachyderes: 43, macho; 44, fêmea; 45 - 46, $H$. (T.) longicollis: 45, macho; 46, fêmea. Barra $=1 \mathrm{~mm}$.

VAN Dyke (1953) ao descrever Parandra galapagoensis, afirmou: "This species was compared with all Central and South American species in the Britsh Museum of Natural History collection and not found to agree with any. It runs to $P$. brachyderes in Lameere's (1902) key, but differs from a cotype of the same...". No entanto, o autor não a comparou com os síntipos de H. brevicollis (Lameere, 1902), depositados no MNHN e, aparentemente, foi conduzido a erro pela chave apresentada por LAMEERE $(l . c$.):

“e. Métasternum ponctué densément et poilu. - Équateur .. P. brevicollis.

ee. Métasternum ponctué éparsément et presque glabre. Mexique occidental P. brachyderes."

Na realidade, os síntipos de $P$. brevicollis não apresentam o metasterno densamente pontuado e piloso, mas sim, bem brilhante e quase sem pontuação e pêlos, como mostra a foto de um dos síntipos (Fig. 58) e detalhes fornecidos por Gérard 

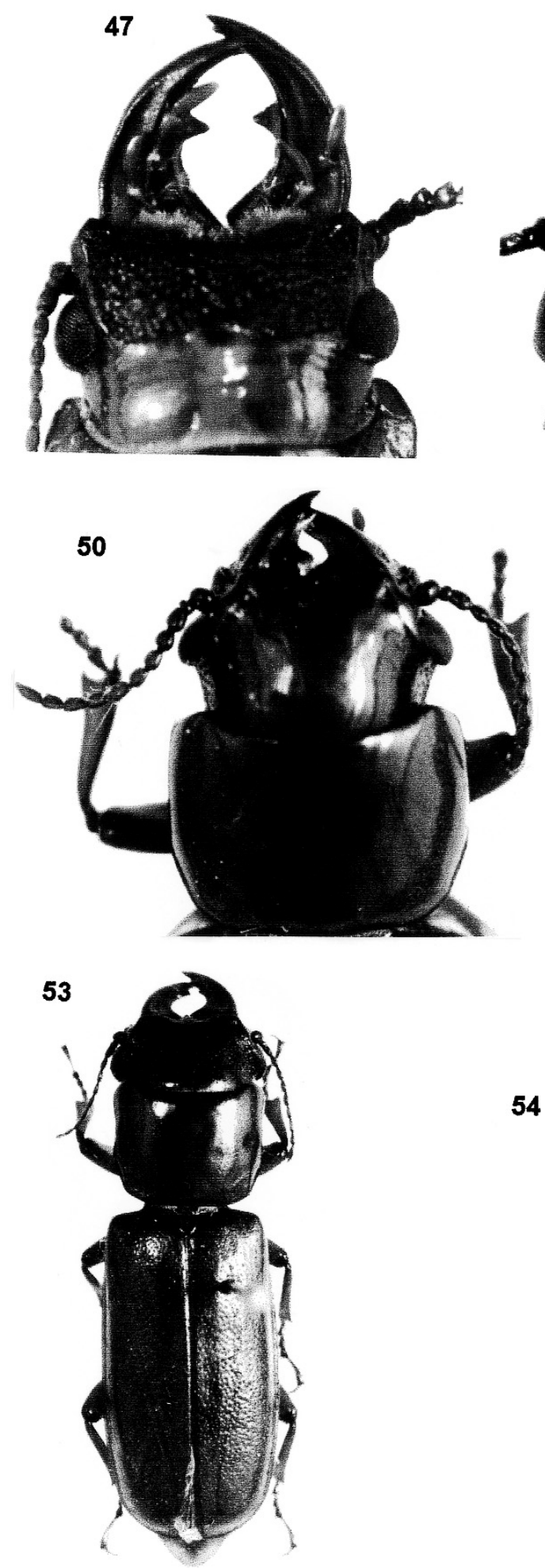

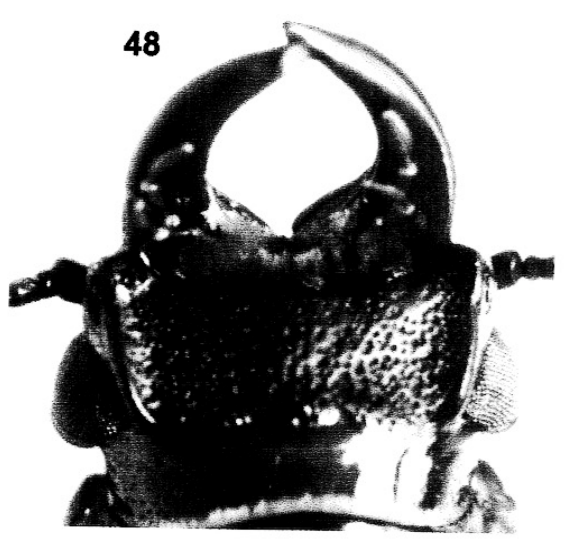

51
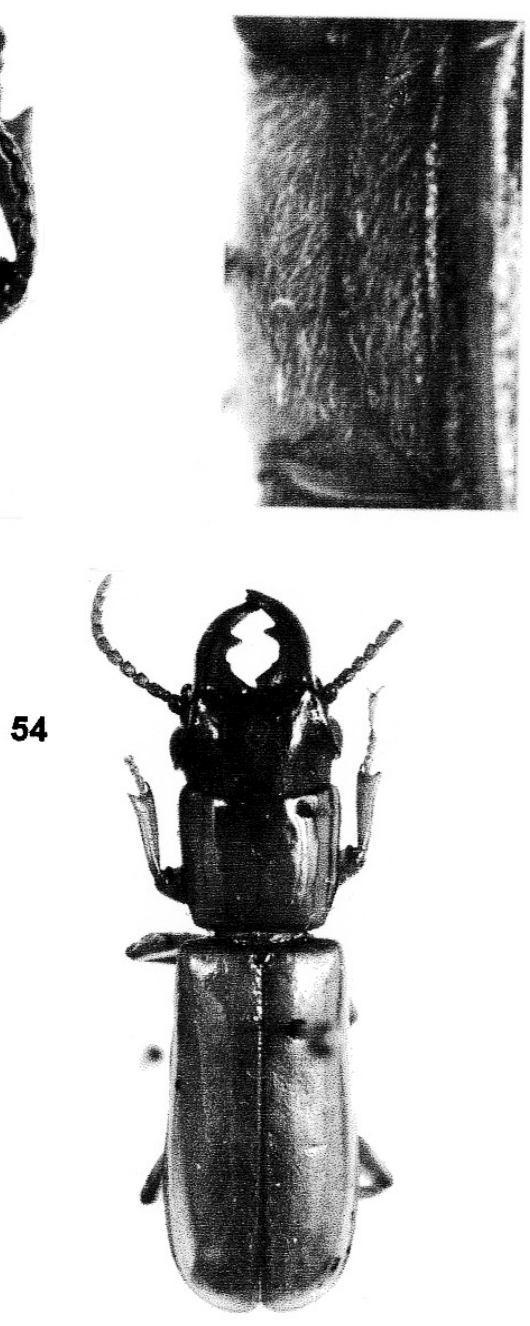

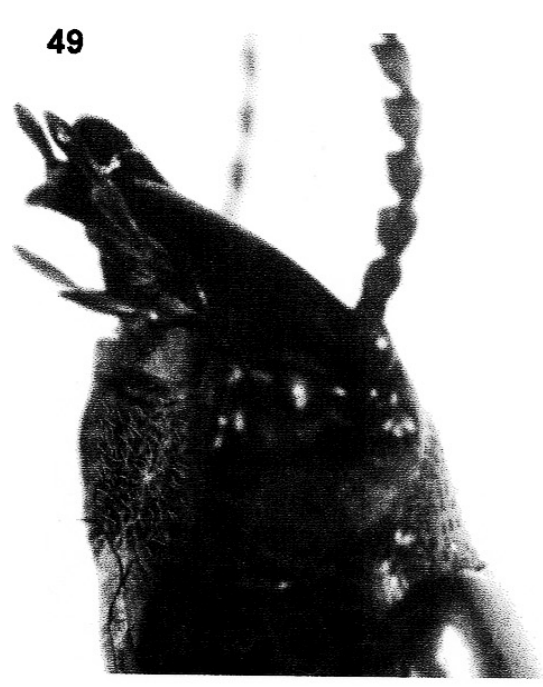

52
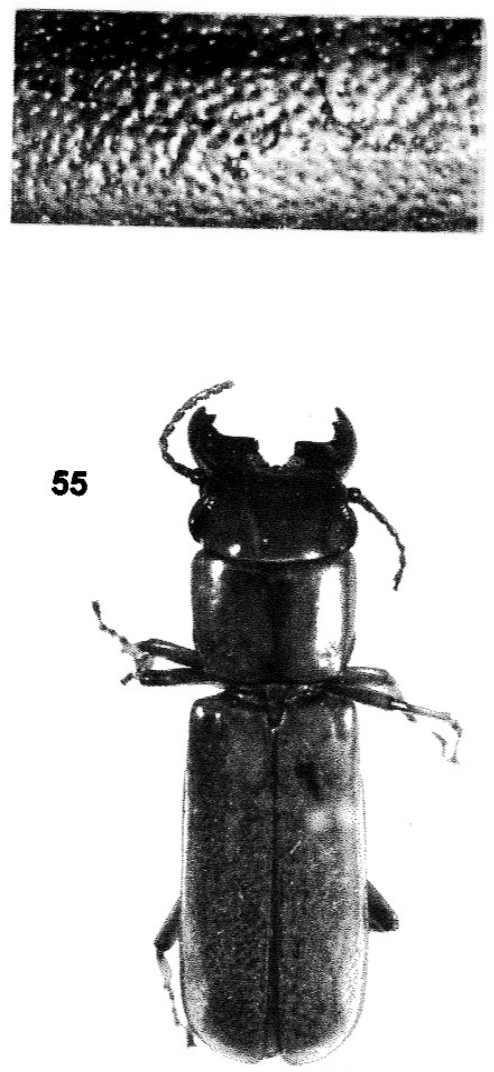

Figs. 47-55. 47, H. (Tavandra) brachyderes, macho, cabeça (ventral); 48, H. (T.) longicollis, macho, cabeça (ventral); 49 - 53, H. (T.) colombica: 49, macho, cabeça (lateral); 50, fêmea, cabeça e pronoto; 51, macho, metepisterno e metasterno (lateral); 52, macho, pontuação elitral; 53, macho, vista dorsal; 54, $H$. (T.) polita, macho, vista dorsal; 55, $H$. (T.) villei, macho, vista dorsal. 

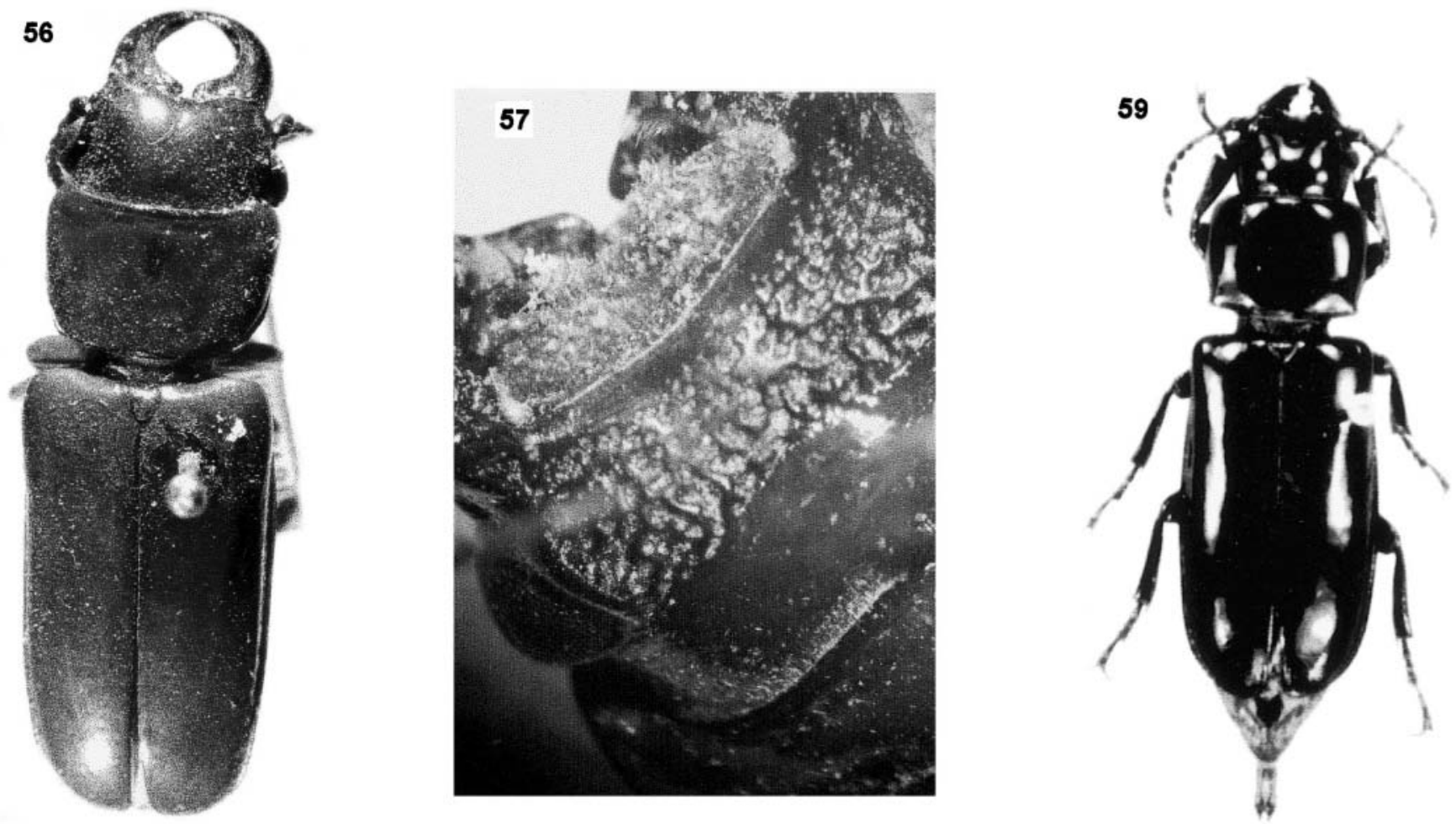

58
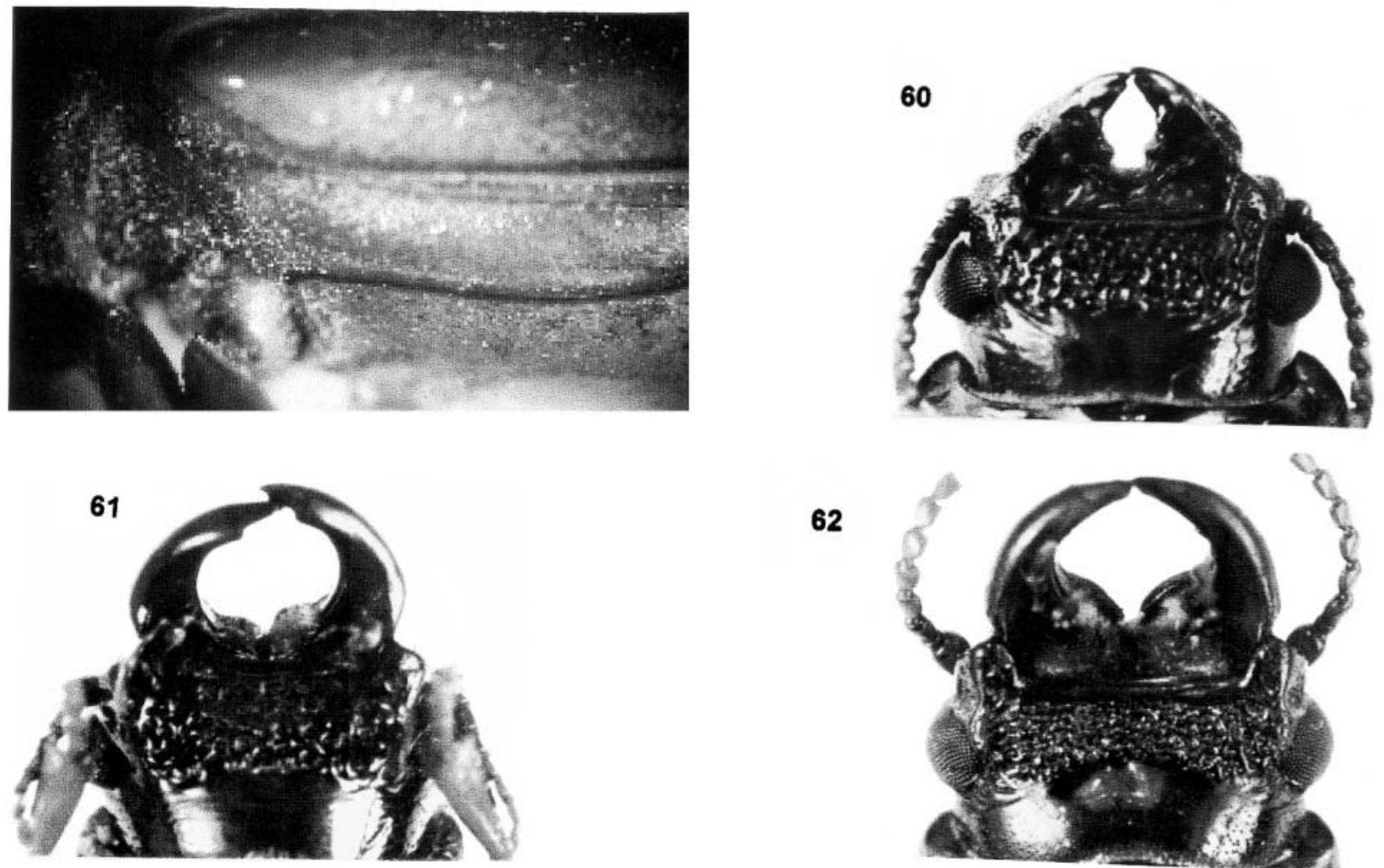

62

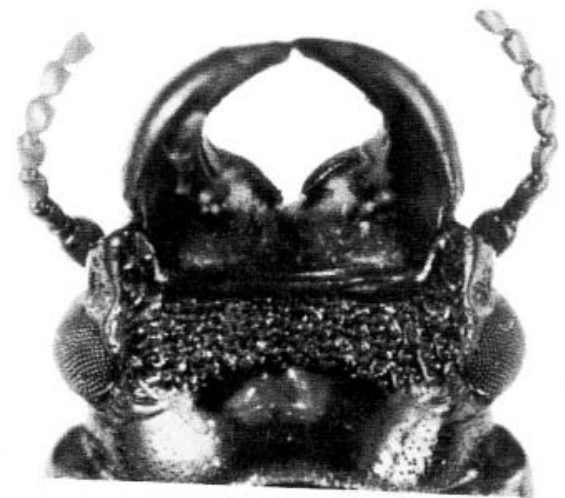

Figs. 56-62. 56 - 58, H. (Tavandra) brevicollis, síntipo macho (Fotos de G. Tavakilian): 56, vista dorsal; 57, submento; 58, metepisterno e metasterno (lateral); 59, H. (H.) conspicua, holótipo fêmea, vista dorsal; 60 - 61, H. (H.) expectata, cabeça (ventral): 60, fêmea; 61, macho; 62, H. (H.) tucumana, macho, cabeça (ventral). 
Tavakilian (comunicação pessoal).

Arigony (1971) ao redescrever o macho de $H$. galapagoensis, declarou: "Submento pouco deprimido, castanho-escuro, com marginação anterior". A figura apresentada pela autora mostra realmente uma marginação estreita e elevada e o espécime parece realmente pertencer à espécie de Van Dyke. No entanto Van Dyke (l. c.), disse: "submentum very coarsely punctured with punctures more or less anastomosing, the front margin smooth and flattened". O submento do exemplar examinado, proveniente de Galápagos (Isla Santiago) concorda com a descrição original, o que demonstra ser um caráter variável nessa espécie (variação relativamente comum na subfamília).

ARIGONY (1978) ao redescrever H. brevicollis, apresentou a foto de um macho e disse: "P. brevicollis foi relacionada por Lameere (1902:70) com P. expectata. Observou-se presentemente, que o submento de ambas é totalmente diverso". Realmente o submento das duas espécies são diferentes, porém, a figura apresentada pertence a uma espécie distinta, obviamente do subgênero $H$. (Zikandra). Além disso, a redescrição não corresponde à $H$. brevicollis.

Pelo estudo dos diapositivos dos tipos, fotos de um dos síntipos de H. brevicollis (Figs. 56 - 58), informações pessoais de Gérard Tavakilian e exame de um macho de Galápagos (Isla Santiago), proponho a sinonímia de Parandra galapagoensis Van Dyke, 1953 com Parandra brevicollis Lameere, 1902.

Designo como lectótipo de $P$. brevicollis, o exemplar macho com 28,2 mm de comprimento(mandíbulas incluídas), depositado no MNHN e que porta seis etiquetas (inclusive uma de lectótipo, embora o status nunca tenha sido formalizado): 1. Quadrada (primeira linha impressa, segunda e terceira manuscritas) - MUSEUM PARIS / Equateur (Loja) / Abbé David $1885 ; 2$. Redonda (face superior verde e face inferior, escrita, branca) - $185185 ; 3$. Grande e manuscrita - Parandra? Loja Ecuador; 4. Identificação (manuscrita, com exceção de A. Lameere det.) - Parandra brevicollis Lam. / A. Lameere det. 1898; 5. Photo No / 28 / 2-29; 6. Lectotype (vermelha).

\section{Hesperandra (Hesperandra) Arigony 1977}

Parandra (Hesperandra) Arigony, 1977: 163; 1978: 119, 130; Monné \& Giesbert, 1994: 1 (cat.); Monné, 1994: 5 (cat.); Martínez, 2000: 79 .

Hesperandra; Villiers, 1980: 137; Chemsak, 1996: 5; Tavakilian, 2000: 158; Santos-Silva, 2001: 221.

Parandra (Archandra) Lameere, 1912: 114 (partim); 1913: 4 (cat., partim); 1919: 15 (partim); Zikán, 1948: 25 (partim); Linsley, 1962: 3 (partim).

Espécie-tipo: Parandra expectata Lameere, 1902, designação original.

Borda ocular posterior (Fig. 63) moderadamente saliente. Submento (Figs. 60-62) enegrecido, com pêlos evidentes e esparsos, pontuação grossa (geralmente anastomosada); borda anterior elevada em toda extensão nos dois sexos ou, nos machos, apenas indicada próximo aos ápices genais. Área ventral das genas (Figs.60-62) mais baixa do que o submento ou no mesmo nível, não-carenada ou com carena inconspícua. Mandíbulas grandes e falciformes nos machos (menores e
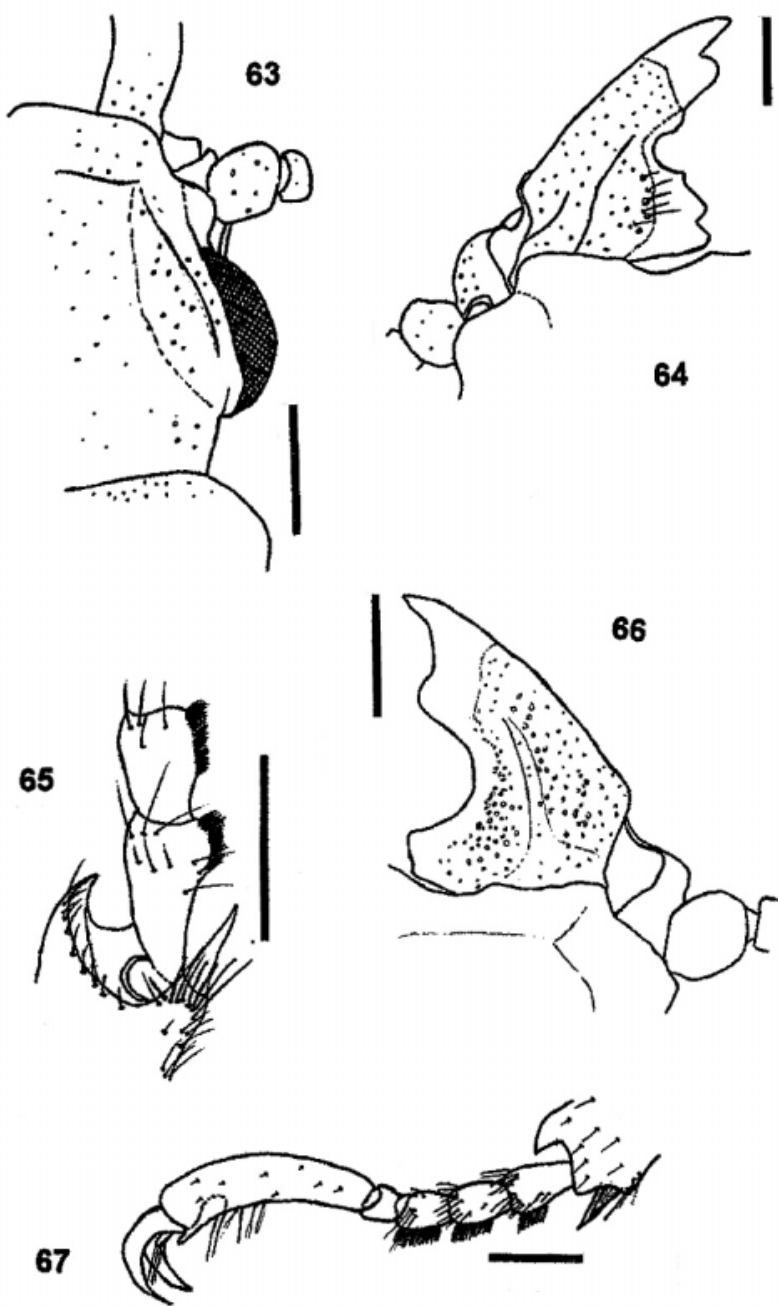

Figs. 63-67. Hesperandra (Hesperandra) tucumana: 63, macho, projeção da borda ocular posterior; 66, fêmea, mandíbula direita (dorsal); H. (H.) expectata: 64, fêmea, mandíbula esquerda (dorsal); 65 e 67, macho, tarsômeros. Barra $=1 \mathrm{~mm}$.

menos curvadas nos exemplares minor); nas fêmeas são menores com a face externa sub-reta. Antenas com área sensorial dos antenômeros III-XI dividida por carena. Protórax com ângulos posteriores bem marcados e aguçados nos machos; arredondados ou obtusos nas fêmeas; marginação lateral incompleta ou nula nos machos e completa nas fêmeas. Tarsômeros II (Figs. 65, 67) com aproximadamente três quartos do comprimento do primeiro.

Chave para as espécies de Hesperandra (Hesperandra).

1. Metepisternos e laterais do metasterno com pontuação densa e pilosidade evidente. BOLÍVIA H.(Hesperandra) conspicua (Tippmann, 1960)

Metepisternos com pilosidade restrita à base; metasterno com pêlos curtos junto às mesocoxas 2

2(1). Machos com marginação lateral do protórax nula ou 
presente apenas no quarto basal; mandíbulas das fêmeas com margem interna côncava (Fig. 66). ARGENTINA (Catamarca, Salta, Tucumán) .... H. (Hesperandra) tucumana (Zikán, 1948)

Machos com marginação lateral do protórax na metade ou dois terços basais; mandíbulas das fêmeas com reentrância central na margem interna (Fig. 64). BRASIL (Bahia até Rio Grande do Sul), ARGENTINA, PARAGUAI, URUGUAI .

$$
\text { H. (Hesperandra) expectata (Lameere, 1902) }
$$

Comentários. Não pude examinar o holótipo de $H$. conspicua e tão pouco obter espécimes que se enquadrassem na descrição original. $H$. conspicua parece diferir de $H$. tucumana por apresentar a pilosidade e pontuação dos metepisternos e partes laterais do metasterno bem mais abundantes. TIPPMANN (1960) afirmou que o holótipo (Fig. 59) possui perto da base no disco do pronoto, nos dois lados, uma cova pequena e funda (nãovisível na foto apresentada no trabalho original), e que ele não observou tal particularidade, nem vagamente, em nenhuma outra espécie do gênero. Essas "covas" são encontradas freqüentemente em exemplares major de $H$. tucumana e $H$. expectata, apesar de nunca tê-las visto profundas. TIPPMANN (l. c.) disse também não conhecer nenhuma espécie da subfamília coletada a $2100 \mathrm{~m}$ de altitude, porém, já examinei exemplares de $H$. colombica coletados a $2650 \mathrm{~m}$ de altitude.

ARIGONy (1978) redescreveu a fêmea e descreveu o macho de H. conspicua. No entanto, a fêmea representada (Figs. 30 e 31) pertence à outra espécie, pois apresenta a forma do protórax totalmente diferente, além da pontuação do submento não coincidir com a descrição original: "Kehle am Vorderrand quergekielt, woran sich eine grob und raspelig skulptierte Zone anschließt". Também o macho representado (ARIGONY, l. c., Figs. 28 e 29), não pertence à espécie em questão. A fêmea é muito semelhante às de $H$. tucumana e $H$. expectata, sendo possível inferir que o macho também é semelhante aos dessas espécies. É possível, também, que $H$. (H.) conspicua seja sinônima de H. tucumana.

Agradecimentos. Ao Dr. Ubirajara R. Martins (MZSP) pelo constante apoio e incentivo. Ao Dr. Miguel A. Monné (MNRJ), Dra. Maria Helena M. Galileo (MCNZ), Claudia Martínez (UNCB) e Dr. Fernando Fernandez (IAHC) pelo empréstimo de material para estudo. Ao Dr. Sebastião de Oliveira (FIOC) por permitir o estudo dos tipos depositados naquela instituição. Ao Dr. Gérard L. Tavakilian (MNHN) pelo empréstimo e doação de espécimes e exame e envio de fotos dos tipos depositados em Paris. A Christiana Klingenberg, pela tradução da descrição original de $H$. (H.) conspicua.

\section{REFERÊNCIAS}

Arigony, T. H. A. 1971. Notas sobre Parandrinae (Coleoptera, Cerambycidae), III. Redescrição de Parandra galapagoensis Van Dyke, 1953. Revista Brasileira de Entomologia 15(3): 15-20. Arigony, T. H. A. 1977. Notas sobre Parandrinae (Coleoptera, Cerambycidae) V. Redescrição de Parandra (Archandra) caspia Ménétriès, 1832. Revista Brasileira de Entomologia 20(3/4):
159-164.

Arigony, T. H. A. 1978. Revisão do gênero Parandra (Coleoptera, Cerambycidae). 1. O Subgênero Hesperandra Arigony 1977. Revista Brasileira de Entomologia 22(3/4): 119-159.

Blackwelder, R. E. 1946. Checklist of the Coleopterous Insects of Mexico, Central America the West Indies, and South America, Part 4. Bulletin United States National Museum 185: 551-763.

Chemsak, J. A. 1996. Illustrated Revision of the Cerambycidae of North America. I. Parandrinae, Spondylidinae, Aseminae, Prioninae. Burbank, Wolfsgarden Books, $x+149$ p., 10 est.

Gara, R. I. \& G. Onore. 1989. Entomologia Florestal. Ministerio de Agricultura y Granaderia, Quito, $267 \mathrm{p}$.

Lameere, A. 1902. Revision des Prionides. Annales de la Société Entomologique de Belgique 46(3): 59-111.

Lameere, A. 1912. Revision des Prionides. Addenda et corrigenda. Mémoires de La Société Entomologique de Belgique 21: 113117.

Lameere, A. 1913. Coleopterorum Catalogus, pars 52, Cerambycidae: Prioninae. Berlin, W. Junk, $180 \mathrm{p}$.

Lameere, A. 1919. Genera Insectorum, Coleoptera, Fam. Cerambycidae, Subfam. Prioninae. Bruxelles, P. Wystsman, 172: 1-189.

Linsley, E. G. 1962. The Cerambycidae of North America. Part II. Taxonomy and classification of the Parandrinae, Prioninae, Spondylinae and Aseminae. University of California. Publications in Entomology 19: 1-102, 1 est., 34 figs.

Linsley, E. G. 1977. Insects of the Galapagos (Supplement). Occasional Papers of the California Academy of Sciences 125: 1-50.

Linsley, E. G. \& J. A. Chemsak. 1966. Cerambycidae of the Galapagos Islands. Proceedings of the California Academy of Sciences (4) 33(8): 197-236.

Linsley, E. G. \& R. L. Usinger. 1966. Insects of the Galápagos Islands. Proceedings of the California Academy of Sciences (4) 33(7): 113-196.

Maes, J.-M.; A. Allen; M. A. Monné \& F. T. Hovore. 1994. Catálogo de los Cerambycidae (Coleoptera) de Nicaragua. Revista Nicaraguense de Entomologia 27: 1-58.

Martínez, C. 2000. Esacarabajos Longicornios (Coleoptera: Cerambycidae) de Colombia. Biota Colombiana 1(1): 76-105.

Melzer, J. 1919. Os longicorneos brazileiros da subfamilia "Prioninae". Revista do Museu Paulista 11: 1-208.

Monné, M. A. 1994. Catalogue of the Cerambycidae (Coleoptera) of the Western Hemisphere. Part XII. São Paulo, Sociedade Brasileira de Entomologia, $56 \mathrm{p}$.

Monné, M. A. \& E. F. Giesbert. 1994. Checklist of the Cerambycidae and Disteniidae (Coleoptera) of the Western Hemisphere. Burbank, Wolfsgarden Books, xiv $+410 \mathrm{p}$.

Santos-Silva, A. 2001. Parandrinae Neotropicais (Coleoptera, Cerambycidae) II: espécies de Hesperandra Arigony, 1977 com submento elevado e marginação lateral do protórax dos machos incompleta. Revista Brasileira de Entomologia 45(3): 221-241, 93 figs.

SAntos-Silva, A. 2002. Notas e descrições em Parandrini (Coleoptera, Cerambycidae, Parandrinae). Iheringia, Série Zoologia, 92(2): 2952, 56 figs.

Tavakilian, G. 2000. Les Parandrinae de Guyane (Coleoptera, Cerambycoidea). Coléoptères 6(11): 147-174.

Tippmann, F. F. 1960. Studien über neotropische Longicornier III. (Coleoptera, Cerambycidae). Koleopterologische Rundschau 3738: $82-217$.

VAN DYKe, E. C. 1953. The Coleoptera of the Galapagos Islands.Occasional Papers of the California Academy of Sciences 22: 1-181.

ViLliers, A. 1980. Coléoptères Cerambycidae des Antilles Françaises I. Parandrinae, Prioninae, Lepturinae. Annales de la Société Entomologique de France (N.S.) 16(1): 133-157.

ZiKÁN, J. F. 1948. O gênero Parandra Latr., 1804, com a descrição de 14 espécies novas (Col. Cerambyc.). Revista de la Sociedad Entomológica Argentina 14: 22-54, 4 est. 